\title{
176. A Revision of the Spiniferous Species of "Cynthia" (Ascidiae Simplices), with Description of a New Species.
}

\author{
By Asajiro OkA, M.I.A. \\ Zoological Institute. Higher Normal School, Tokyo.
}

(Rec. Dec. 6, 1926. Comm. Dec. 12, 1926.)

When Herman published his " Revised Classification of the Tunicata," ") in 1891, only two species of Cynthia were known., whose test was beset with remarkably long, branched, and echinated spines, namely :C. echinata Linné from Northern Europe and C. hilgendorfi Traustedt from Japan. Since that time several species have been added to the group, such as C. spinifera Herdman² from Australia, C. owstoni Oka, C. ritter $i$ Oka, and C. igaboja $\mathrm{Oka}^{3}$ from Japan, and C. okai Ritter ${ }^{4}$ from California. An old species from Puget Sound, C. villosa Stimpson, as re-described by Herdman," also belongs undoubtedly to the same group.

In the autumn of last year (1925) I received from the Marine Biological Station at Misaki a large specimen of a spiniferous Cynthia, which belonged apparently to the above mentioned group, but was quite distinct from all the species previously known. The new species, which I propose to name C. pachyderma, on account of the unusually thick test, may be characterised as follows:-

\section{Cynthia pachyderma nov. sp.}

Extcrnal Appearance. The body is irregularly ovoid in shape; it is elongated antero-posteriorly, and is attached by a comparatively small area on the left side of the ventral surface. Tbe branchial aperture is at

1) Herdiax, W. A. Revised Classification of the Tunicata. Journ. Linn. Soc., Zool., Vol. XXIII. 1891.

2) Herdman, W. A. Descriptive Catalogue of the Tumicata in the Australian Museum. 1899.

3) OKA, A. Notizen über japanische Asciden, I. Annot. Zool. Japon. Vol. VI. 1906.

4) Ritter, W.E. The Ascidians cellected by the U.S. Fisheries Bureau Steamer Albatross on the Coast of California during the Summer of 1904. Univ. Calif. Publ. Zool., Vol. IV. 1907.

5) Herdun, W. A. Description of Some Simple Ascidians collected in Puget Sound. Trans. Liverpool Biol. Soc., Vol. XII. 1898. 
the anterior end, and is directed dorsally; the atrial is on the dorsal median line about two fifths of the way down. The siphons do not project at all above the general surface of the body, but the position of the apertures is indicated by tufts of thick echinated spines.

The surface is very uneven, and is deeply wrinkled and rather rough. The colour is reddish brown.

Length of the body $125 \mathrm{~mm}$, breadth of the body $100 \mathrm{~mm}$.

The Test is very thick $(7 \mathrm{~mm}$.$) ; it is tough and opaque, between$ cartilaginous and coriaceous in texture. The superficial layer is reddish, the inner surface pale flesh colour, except around the apertures where it is dark red.

The Mantle is pretty thick and yellowish; the muscular layer is well developed, with fibres running in all directions. Viewed from inside, a number of strong muscle bands are seen radiating from the apertures, both of which are distinctly four-lobed.

The Tentacles are compound and bushy, they are about twenty-four in number, placed large and small alternately.

The Branchial Sac has nine folds on each side; they are all broad and well developed. The internal longitudinal bars are numerous, about 35 on the folds and 6 or 7 in the interspaces. The branchial membrane is exceptionally strong on account of the transverse vessels being very stout, the thinnest of which are as wide as the rows of stigmata. The meshes are elongated transversely and contain each five or six short and wide stigmata.

The Dorsal Tubercle forms a double cone, with complicated meandering grooves on the surface.

The Dorsal Lamina is replaced by a double row of fine, closely placed, pointed languets.

The Alimantary Caral is situated on the left side of the body; it forms a rather wide loop. The oesophageal opening lies between the posterior ends of the rows of languets. The stomach is not large, nor clearly set off from the intestine ; there are hepatic appendage with lobulated surface projecting from the ventral edge of the stomach. The intestine is of equal width throughout and ends with the rectum attached to the dorsal edge of the branchial sac. The anus is a simple round opening with a distinct rim.

The Gonads are present on both sides of the body. They form two flattened masses, each consisting of ten to twelve elongated hermaphroditic glands with separate vas deferens and oviducts. The right mass, which is rather the larger of the two, is attached to the inner surface of 
the mantle; the left lies in the intestinal loop, with the gonoducts adhering to the mesial wall of the intestine.

As all the spiniferous species of Cynthia, except $C$. spinifera and $C$. okai, are represented in my collection, I have undertaken a comparative study of their characters, both external and internal. From the results obtained, it is quite clear that they do not constitute a natural group, but must be regarded as being polyphyletic in origin. As shown in the following table, the species differ in most important anatomical characters, such as the structure of the branchial sac and the form of the dorsal lamina.

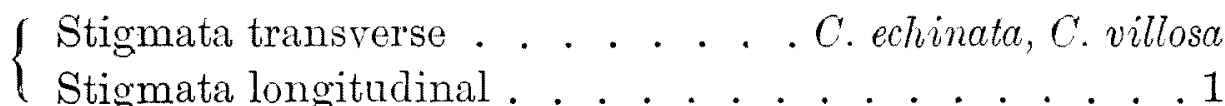

$1\{$ Dorsal lamina a plain membrane . . . . . C. spinifera

Dorsal lamina in the form of languets . . . . . . . . 2

$2\{$ Siphons projecting . . . C. hilgendyrfi, C. owstoni C. ritteri

Siphons inconspicuous . . . . . . . . . . . . . 3

$3\{$ Spines all over the surface . . . . C. igaboja, C. okai

Spines only around the apertures . . . . C. pachyderma

As first pointed out by Alder, in 1863, C. echinata is remarkable in having the branchial stigmata placed transversely, in place of longitudinally as in nearly all Ascidians. C. villosa agrees with $C$. echinata in this respect. The genus Cynthia comprises at present more than one hundred species, and it will soon be found necessary to divide it into a number of subgenera or genera; in that case, the first two species will have to be placed in a different subgenus or genus from the remaining. ones. As to $C$. spinifera it will be necessary either to remove it to the genus Microcosmus or to re-consider the diagnoses of the two genera, as their distinction seems somewhat too arbitrary, being based solely upon the configuration of the dorsal lamina. The remaining species form a natural group, their specific differences being all referable to characters of less importance. It is extremely interesting to note that such complicated structures as the echinated spines should have developed independently in different groups of Cynthia as a result of convergent modification. 